\title{
Beyond osmolytes and transcription factors: drought tolerance in plants via protective proteins and aquaporins
}

\author{
S.S. HUSSAIN ${ }^{1} *$, M.T. IQBAL ${ }^{1}$, M.A. ARIF ${ }^{2}$ and M. AMJAD ${ }^{3}$ \\ Institute for Molecular Physiology and Biotechnology of Plants, University of Bonn, \\ Kirschallee 1, D-53115 Bonn, Germany ${ }^{1}$ \\ Institute for Genetics, Heinrich-Heine-University Düsseldorf, Universitätsstr. 1, D-40225 Düsseldorf, Germany ${ }^{2}$ \\ Institute of Horticultural Sciences, University of Agriculture, Faisalabad-38040, Pakistan ${ }^{3}$
}

\begin{abstract}
Mechanisms of drought tolerance have been studied by numerous groups, and a broad range of molecules have been identified to play important roles. A noteworthy response of stressed plants is the accumulation of novel protective proteins, including heat-shock proteins (HSPs) and late embryogenesis abundant (LEA) proteins. Identification of gene regulatory networks of these protective proteins in plants will allow a wide application of biotechnology for enhancement of drought tolerance and adaptation. Similarly, aquaporins are involved in the regulation of water transport, particularly under abiotic stresses. The molecular and functional characterization of protective proteins and aquaporins has revealed the significance of their regulation in response to abiotic stresses. Herein, we highlight new findings regarding the action mechanisms of these proteins. Finally, this review also surveys the current advances in engineering drought tolerant plants, particularly the engineering of protective proteins (sHSPs and LEA) and aquaporins for imparting drought stress tolerance in plants.
\end{abstract}

Additional key words: abiotic stress, heat-shock proteins, late embryogenesis abundant proteins, transgenic plants

\section{Introduction: from green revolution to gene revolution}

Global food shortage due to abiotic stresses (drought, salinity, extreme temperatures) and high human population directed plant scientists towards gene revolution following green revolution. This approach is commonly referred to as genetic engineering/transgenic approach. Transgenic approaches offer new opportunities to improve tolerance to abiotic stresses. Drought is one of the greatest worldwide environmental constraints for agricultural productivity (Boyer 1982, Bray et al. 2000). Improving crop resistance to drought stress is a long standing goal of agricultural biotechnology (McCue and Hanson 1990, Jain and Selvaraj 1997). The present genetic engineering strategies rely on the transfer of one or several genes to the target plant. Overproduction of these genes in transgenic plants enhances their protective effects against not only drought but also other abiotic stresses. These genes are either involved in signaling and/or regulatory pathways, or that encode enzymes leading to the synthesis of functional and structural protectants, as reviewed by Wang et al. 2003, Vinocur and Altman 2005, Valliyodan and Nyugen, 2006, Sreenivasulu et al. 2007, Kathuria et al. 2007, Bartels and Hussain 2008, Hu et al. 2010, Hussain et al. 2011a,b.

Efforts to improve crop performance under drought stress were not yet so successful for two main reasons: incomplete understanding of underlying fundamental mechanisms of stress tolerance and lack of knowledge of the interactions of different stressors. Engineering drought tolerance in crop plants has huge economic importance. Genetic engineering for drought stress tolerance was limited in the pre-genomics era due to limited availability of genes and specific promoters. Now it is possible to study many genes simultaneously on a genome wide-scale with respect to their structure and

Received 8 June 2010, accepted 7 September 2010.

Abbreviations: ABA - abscisic acid; HSPs - heat-shock proteins; LEA - late embryogenesis abundant; MIPs - major intrinsic proteins; PIPs - plasma membrane intrinsic proteins; TIPs - tonoplast intrinsic proteins; WUE - water use efficiency.

Acknowledgement: This work was supported by Higher Education Commission (HEC) of Pakistan by a project grant to SSH.

* Corresponding author; fax: (+49) 22873 1697, e-mail: shussain@uni-bonn.de 
function. However, the multigenic nature of complex mechanisms of stress tolerance and the potential side effects on plant growth make this task difficult. In the current article, we provide a comprehensive outline of transgenics developed so far for drought tolerance by using LEA, sHSPs and aquaporins.

\section{Transgenic plants harboring transcription factors and osmoprotectants for conferring drought stress tolerance}

Recent progress has been made in our understanding of gene expression, transcriptional regulation and signal transduction in plant responses to drought (Shinozaki et al. 2003, Yamaguchi-Shinozaki and Shinozaki 2005). On the other hand, molecular and genomic analyses have facilitated gene discovery (Seki et al. 2001, Abe et al. 2003, Tran et al. 2004, Seki et al. 2007) and enabled genetic engineering using several functional or regulatory genes to activate or repress specific or broad pathways related to drought/salinity tolerance in plants (Trujillo et al. 2009). Progress in plant modification for enhanced drought tolerance through manipulation of either transcription and/or signaling factors in transgenic plants have been impressive during the last two decades (Hussain et al. 2011b). Successful examples are transgenic crops engineered with genes encoding the DREBs/CBFs transcription factors (tomato - Hsieh et al. 2002, rice - Dubouzet et al. 2003, Oh et al. 2005, Ito et al. 2006, Wang et al. 2008 and wheat - Pellegrineschi et al. 2004). The transgenic plants showed increased stress tolerance as well as the over induction of downstream stress related genes and/or higher contents of soluble sugars and proline (Gilmour et al. 2000, Ito et al. 2006).

Despite DREB/CBF, other transcription factors like members of the MYB, MYC, ERF, bZIP, and WRKY transcription factor families have already been implicated in the regulation of stress responses (Schwechheimer et al. 1998, Singh et al. 2002). Therefore, these are attractive targets for the purpose of gene regulation and manipulation of the regulatory elements, which may be beneficial under abiotic stresses (Nakashima et al. 2007, $\mathrm{Hu}$ et al. 2008, Jung et al. 2008, Trujillo et al. 2008, Yu et al. 2008, Xiang et al. 2008, Zou et al. 2008, Qiu and Yu 2009, Zhang et al. 2009, Abdeen et al. 2010, Agrawal and Jha 2010, Hussain et al. 2011b).

Transcriptional factors can be a valuable resource in transgenic technology, attributing novel traits to the transgenic plants. This and related technologies are poised to become important genomic tools that will allow researchers to rapidly obtain functional information.

Metabolic engineering for increased osmolyte contents was successful in several plants subjected to stress (Wang et al. 2003), although real advantages of such a strategy are always a subject of debate (Serraj and Sinclair 2002). Such osmoprotectants serve to decrease the osmotic potential of the plants in the cytoplasm and can also stabilize different proteins and the membranes under various abiotic stresses (Bohnert and Shen 1999, McNeil et al. 1999). Several osmoprotectants like proline (Bertrand and Paquin 1991, Naidu et al. 1991, Delauney and Verma 1993, Murelli et al. 1995, Wanner and Juntilla 1999), 3-dimethylsulfoniopropionate (McNeil et al.1999), trigonelline and betaines (Naidu et al. 1991, Nomura et al. 1995, McNeil et al.1999, Nuccio et al. 1999) fructans and trehalose (Pilon-Smits et al. 1995, Crowe et al. 1998, Goddijn and van Dun 1999, Iturriaga et al. 2000) and polyols (Bohnert and Jensen 1996; Sheveleva et al. 1997, 1998) have been identified in stressed plants. However, many crops lack the ability to synthesize these special osmoprotectants that are naturally accumulated by the stress tolerant organisms. For example, several taxonomically distinct species, including spinach and wheat, are natural accumulators of glycine betaine while others, including Arabidopsis, rice, tomato, and potato are considered to be non-accumulators. Therefore, the widely adopted strategy till now is to engineer or overexpress certain osmolytes which serves as potential route to breed stress tolerant crops. This strategy has resulted in several successful studies where different osmoprotectants have been overexpressed, like proline (Mani et al. 2002, Simon-Sarkadi et al. 2005, Yamada et al. 2005, Gubis et al. 2007, Vendruscolo et al. 2007, Chen et al. 2009, Kumar et al. 2010), glycine betaine (Park et al. 2004, Quan et al. 2004, Lv et al. 2007, Park et al. 2007, Ahmad et al. 2008) sugars and sugar alcohols (Chen and Murata 2002, Cortina and Culianez-Macia 2005, Karim et al. 2007, Miranda et al. 2007, Paul et al. 2008, Stiller et al. 2008, Suzuki et al. 2008, Livingston III et al. 2009, Suárez et al. 2009).

A variety of genes has been identified and employed to generate transgenic plants that accumulate osmoprotectants and they are tolerant to drought and other abiotic stresses. These studies emphasize the importance of different osmoprotectants in stress tolerance and demonstrate that the modification of drought stress tolerance by manipulation of these compounds is a valuable alternate in plants.

\section{Transgenic plants harboring protective proteins for enhanced tolerance}

To cope with the environmental stresses, plants activate a large set of genes, which lead to the accumulation of specific stress-associated proteins (Vierling 1991, Ingram and Bartels 1996, Bohnert and Sheveleva 1998, 
Thomashow 1999, Hoekstra et al. 2001). Heat-shock proteins (HSPs) and the late embryogenesis abundant (LEA)-type proteins are induced by stress and accumulate in huge amounts upon drought, salinity, and extreme temperature stress (Table 1). These have been shown to play a role in the cellular protection during stress (Vierling and Kimpel 1992, Boston et al. 1996, Close 1996, Ingram and Bartels 1996, Waters et al. 1996, Thomashow 1998). Recently, Hu et al. (2010) advanced multifunctional gene concept and defined it that a multifunctional gene is a gene that can regulate several kinds of traits and also manifest several kinds of functions. Based on this hypothesis, sHSPs, LEA and aquaporin proteins perform several functions in plants. This review summarizes the progress of plant engineering using these three protein groups for improving drought stress tolerance.

HSPs are molecular chaperones : HSPs are produced in response to elevation in temperature and certain other stresses. In response to abiotic stresses, certain enzymes and proteins are affected and become dysfunctional. Therefore, maintaining the proteins in their functional conformations and preventing the aggregation of proteins are particularly important for cell survival under stress conditions. The isolated HSPs were shown to protect up to $75 \%$ of soluble proteins from heat denaturation in vitro (Jinn et al. 1995). Many stress-responsive proteins, especially HSPs, have been shown to act as molecular chaperones and maintain homeostasis of protein folding and so are responsible for the acquisition of stress tolerance (Vierling 1991, Hendrick and Hartl 1993, Boston et al. 1996, Hartl 1996, Waters et al. 1996, Török et al. 2001).

Among the five conserved families of HSPs (HSP100, HSP90, HSP70, HSP60 and sHSP), the small heat-shock proteins (sHSPs) have been shown to be the most prevalent in plants. Plant HSPs consist of a few high molecular mass proteins and a complex group of low molecular mass proteins with molecular sizes ranging from 15 to $30 \mathrm{kDa}$ (Vierling 1991). All the plant sHSP proteins are encoded by the nuclear genes and are divided into six classes based on intracellular location and sequence similarity into cytosolic class I, cytosolic class II, chloroplast, mitochondria, endoplasmic reticulum and peroxisome sHSPs (Low et al. 2000, Ma et al. 2006, Kotak et al. 2007, Mamedov and Shono 2008, Siddique et al. 2008). It is believed that accumulation of HSPs plays a pivotal role in abiotic stress tolerance in plants (Sun et al. 2002, Sorensen et al. 2003). The sHSPs, as well as other HSPs, are believed to play an important role in plant stress tolerance to extreme temperatures (Malik et al. 1999, Lopez-Matas et al. 2004, Sanmiya et al. 2004 Charng et al. 2006, Jiang et al. 2009), salinity (Harington and Alm 1988, Hamilton and Heckathorn 2001, Liu et al. 2006), toxic metals (Wollgiehn and Neumann 1995), chilling (Sebehat et al. 1996, Sato et al. 2001), oxidative stress (Banzet et al. 1998, Lee et al. 2000, Neta-Sharir et al. 2005, Volkov et al. 2006), dehydration (Campbell et al. 2001, Liu et al. 2006, Sato and Yokoya 2008), abscisic acid (ABA) treatment (Campbell et al. 2001), mechanical injury and salicylic acid treatment (Chang et al. 2007). The protective effects of HSPs can be attributed to the network of the chaperones acting coordinately (Wang et al. 2005). This is also clear from the fact that more than 70 putative HSP genes were found in rice genome by searching the Rice Genome Annotation (Ouyang et al. 2007). Some of these genes have been cloned and characterized (Pareek et al. 1998, Lee et al. 2000, Guan et al. 2004, Murakami et al. 2004, Liu et al. 2006, Chang et al. 2007, Sato and Yokoya 2008, Hu et al. 2009) while most of them remained to be functionally annotated.

Transgenic Arabidopsis plants that overexpressed class II HSP $17.6 A$ and accumulated high content of HSP17.6A protein showed increased tolerance to drought and salt stress (Sun et al. 2001). The major chaperone activity of SHSPs is to bind and hold the denatured substrates in a folding-competent state for subsequent refolding by a chaperone network (Horwitz 1992, Ehrnsperger et al. 1997, Lee et al. 1997, Veinger et al. 1998, Haslbeck et al. 1999, Ding and Candido 2000, Studer and Narberhaus 2000). However, some members of the plant sHSPs can also stabilize enzymes or reactivate the inactivated enzymes (Lee et al. 1995, Hook and Harding 1998, Muchowski and Clark 1998, Haslbeck et al. 1999, Smykal et al. 2000, Marini et al. 2000, Sun et al. 2001). Various studies have shown that plant sHSPs are not only expressed in response to heat shock, but also under water, salt, oxidative stresses, and at low temperatures (Almoguera et al. 1993, Alamillo et al. 1995, Sebehat et al. 1998, Harndahl et al. 1999, Hamilton and Heckathorn 2001). Cho and Hong (2006) reported that the transgenic tobacco plants overexpressing NtHSP70-1 exhibited tolerance to water stress by regulating the water flux in these transgenic plants. Recently, transgenic rice plants overexpressing small heat-shock protein sHSP17.7 have been shown to have an enhanced tolerance to drought stress (Sato and Yokoya 2008). In this study, both the transgenic and the control plants withered the same day under severe drought stress. However, only the transgenic seedlings could re-grow after rewatering. This study clearly demonstrated the role of sHSP in subsequent rehydration after the plants have undergone drought stress.

The LEA-type proteins: In addition to HSPs, also LEA-type proteins can confer molecular protection of cellular components during abiotic stresses (Wang et al. 2003). LEA-type proteins have been found in a wide range of plant species where they are synthesized in response to water deficit resulting from desiccation, cold and osmotic stress (Physcomitrella patens - Liang et al. 2004, pea - Grelet et al. 2005, soybean - Shih et al. 2004, rice - Moons et al. 1997, cotton - Galau et al. 1993, radish - Raynal et al. 1990) and salt stress (mulberry Jyothsnakumari et al. 2009). LEA-type proteins are encoded by $R D$ (responsive to dehydration), ERD (early 
responsive to dehydration), KIN (cold inducible), COR (cold regulated), and $R A B$ (responsive to abscisic acid) genes in different plant species (Shinozaki and Yamaguchi-Shinozaki 2000, Zhu 2002). LEA-type proteins fall into a number of families, which have diverse structures and functions (Close 1996, Ingram and Bartels 1996, Thomashow 1998). Till date, the actual function of the LEA-type proteins remains, however, largely unknown. However, some functions have been predicted from their structural characteristics and synthesis during the late stage of embryogenesis and also their induction by stress. It has been suggested that the LEA-type proteins act as water-binding molecules in seeds where they protect other proteins from the harmful effects of desiccation, in ion sequestration and in macromolecule and membrane stabilization against freeze-induced injury (i.e. chaperone-like activity; Dure 1993a,b, Close 1996, Ingram and Bartels 1996, Thomashow 1998, 1999, Vij and Tyagi 2007, Tunnacliffe and Wise 2007).

Transgenic plants overexpressing genes encoding LEA proteins can increase the tolerance to drought, salt, cold and other stresses (Cho and Hong 2006, Jyothsnakumari et al. 2009). For example, constitutive overexpression of the HVA1, a group 3 LEA protein from barley, conferred tolerance to low soil water and salt stress in transgenic rice plants (Xu et al. 1996) due to the cell membrane protection and osmotic adjustment (Babu et al. 2004, Fu et al. 2007). Recently, Ndong et al. (2002) reported that the constitutive expression of a wheat chloroplast LEA-like protein (WCS19) in Arabidopsis resulted in a significant increase in freeze-tolerance. Also the constitutive or stress induced expression of the HVA1 gene resulted in the improvement of the growth characteristics and stress tolerance in terms of increased cell integrity in wheat and rice under water and salt stress conditions (Sivamani et al. 2000, Maqbool et al. 2002, Rohilla et al. 2002, Bahieldin et al. 2005, Oraby et al. 2005). Overexpression of a single/multiple LEA-type protein is not always sufficient to confer stress tolerance to the plants, an example of this is the case where the transgenic tobacco plants that had been transformed with three Craterostigma plantagineum cDNAs, pcC6-19 (homologous with rice rab16), pcC3-06 (homologous with lea D29) and $p c C 27-45$ (homologous with lea 14), expressed high levels of the encoded proteins, but this increase did not result in drought tolerance (Iturriaga et al. 1992). This suggested that there was the possibility that the LEA-type proteins might function synergistically with other molecules. In this respect, overexpression of group 3 LEA genes in Arabidopsis (Figueras et al. 2004) and tobacco (Roychoudhury et al. 2007) showed significant increase in growth rate under stress condition and also resulted in increased osmolyte such as proline, polyamines and sugars production. Similarly, transgenic tobacco overexpressing a PF03760 LEA protein from a resurrection plant Boea hygrometrica exhibited an increased peroxidase and superoxide dismutase activity during drought (Liu et al. 2010). These studies clearly demonstrated that LEA protein can have an indirect effect on the accumulation of protective molecules and stress tolerance can possibly be the result of these protective molecules. Transgenic rice (TNG67) plants, expressing a wheat LEA group 2 protein gene (PMA80) or the wheat LEA group 1 protein gene (PMA1959), had increased tolerance to drought and salt stresses, although their water use efficiency (WUE) was low (Cheng et al. 2002). Besides the protective chaperone-like functions of the LEA proteins, their action against cellular damage has been proposed (Vinocur and Altman 2005), indicating the role of LEA proteins in anti-aggregation of enzymes under dehydration and freezing stress (Goyal et al. 2005). Also recent computational studies have proposed that the LEA type proteins act as chaperone-like protective molecules that function against cellular damage (Wise 2003, Wise and Tunnacliffe 2004). Therefore, engineering plants that produce LEA protein would be a more efficient way to develop a multiple stress-tolerant crop plants without compromising its productivity.

Despite massive data on the LEA proteins expression and their structure (Garay-Arroyo et al. 2000, BiesEtheve et al. 2003, Grelet et al. 2005), little work has been reported on the manipulation of the LEA genes to improve drought resistance (Goyal et al. 2005, Park et al. 2005a, 2005b, Wang et al. 2006, Fu et al. 2007, Jun et al. 2008, Lal et al. 2008, Dalal et al. 2009). It is worth mentioning that none of these authors have evaluated the role of LEA genes under field conditions. Only Xiao et al. (2007) conducted some field studies on transgenic rice carrying the OsLEA3-1 gene under the control of three different promoters. Their results indicate that drought resistance is significantly improved in those transgenic rice which express the OsLEA3-1 transgene controlled by a drought-inducible HVA1 like promoter and a constitutive promoter CaMV 35S. They further described that, apart from improved drought resistance, there are no phenotypic changes, or any yield penalty under field conditions. However, before engineering crop plants with LEA genes, it will be necessary to secure data comparing the efficiency of various members of LEA genes and also the efficiency of single LEA gene in a range of species under multiple abiotic stresses.

\section{Genetic manipulation of aquaporin functions in transgenic plants}

Water movement across the cellular membranes is largely regulated by a family of water channel proteins called aquaporins. Aquaporins belong to the major intrinsic proteins (MIPs) family and facilitate the flow of water across the cellular membranes (plasmalemma and tonoplast), following osmotic or hydrostatic pressure gradients (Chrispeels and Agre 1994, Schaeffner 1998). The biological significance of aquaporins in plants is 
their ability to modulate transmembrane water transport in situations where adjustment of water flow is physiologically critical (for reviews see Baiges et al. 2002, Luu and Maurel 2005). Furthermore, the importance of the ability to increase or decrease the water permeability of a cell is signified by the very high diversity of aquaporin homologues present in plants: genome projects have revealed 35 aquaporins in Arabidopsis (Johanson et al. 2001, Maurel et al. 2002, Quigley et al. 2002, Boursiac et al. 2005), 33 in rice (Sakurai et al. 2005), 36 in maize (Chaumont et al. 2001), 23 in moss (Danielson and Johanson 2008), 37 in tomato (Sade et al. 2009), and 55 in poplar (Gupta and Sankararamakrishnan 2009). The two major subgroups of the aquaporins are the plasma membrane intrinsic proteins (PIPs) and the tonoplast intrinsic proteins (TIPs) (Johnson et al. 1990; Ermawati et al. 2009). PIPs play an important role in controlling the transcellular water transport and are further subdivided into two subfamilies PIP1 and PIP2 (Schaeffner 1998, Chaumont et al. 2000). TIPs seem to be involved in water exchange between the cytosolic and the vacuolar compartments, and are involved in cell osmoregulation (Maurel et al. 1997, Tyerman et al. 1999). Although the discovery of the aquaporins has resulted in a paradigm shift in the understanding of the plant water dynamics, a comprehensive picture of the physiological role of aquaporin in plant remains elusive. However, the highly regulated expression of the aquaporins in plants suggests that the transmembrane water transport may be important in many other processes in addition to those related to transpiration.

The importance of aquaporins in environmental responses has been demonstrated through gene expression analysis and genetic manipulation of the aquaporin functions in plants which provide a promising strategy to address the questions of the overall role of the water molecules in plant homeostasis (Table 1). Antisense inhibition of the PIP aquaporins in tobacco and Arabidopsis resulted in a marked decrease in the plant ability to recover from water stress, suggesting that aquaporin functions, and possibly their adjustment, were of critical importance during this process (Martre et al. 2002, Siefritz et al. 2002). On the other hand, tobacco plants overexpressing $P I P 1 b$ and rice plants overexpressing $H v P I P 2 ; 1$ became hypersensitive to drought and salt stress (Aharon et al. 2003, Katsuhara et al. 2003). Overexpression of $H v P I P 2 ; 1$ in rice negatively affected root and shoot growth under salt stress. In contrast, Lian et al. (2004) identified a rice PIP aquaporin gene $(R W C 3)$ whose expression is induced by osmotic challenge, specifically in a drought-tolerant rice cultivar. Over-expression of this gene in a drought-sensitive rice cultivar, under the control of a stress-inducible promoter, was able to improve the growth performance of this cultivar, specifically under stress. Similarly, $\mathrm{Yu}$ et al. (2005) found that transgenic tobacco overexpressing BnPIP1 showed enhanced drought tolerance. In the current scenario, Jang et al. (2007) examined thoroughly the effects of drought stress on the transgenic Arabidopsis and tobacco plants that constitutively over-expressed the AtPIP 1;4 or AtPIP2;5. Under favorable growth conditions, no significant differences in the growth rates and water transport were found in transgenic plants compared to wild-type plants. However, under drought stress, the transgenic plants over-expressing PIP1;4 or $P I P 2 ; 5$ showed retarded germination and growth as compared with wild-type plants. Recently, overexpression of the Panax ginseng tonoplast aquaporin, PgTIP1, in the Arabidopsis plants showed vigorous plant growth under slight drought stress or favorable growing conditions (Peng et al. 2007).

It is clear from the above discussion that currently, two opposite views exist concerning the aquaporin performance in transgenic plants under water stress. One view is that increased aquaporin levels might provide the plant with additional ability to cope with drought stress (Smart et al. 2001, Lian et al. 2004). The second opinion is that plants avoid excessive loss of water by downregulating aquaporin during dehydration (Aharon et al. 2003, Hachez et al. 2006, Peng et al. 2007). Further work is clearly required to determine the exact functions of aquaporins and the mechanisms by which their overexpression enhances the drought tolerance of transgenic plants.

Recently, two studies clearly demonstrated the effective involvement of aquaporins in conferring stress tolerance in plants. Sade et al. (2009) used a novel approach for the selection of candidate aquaporin for investigating its role in drought stress tolerance. The authors used an effective computational program for selection of candidate tomato aquaporin out of the family of 37 aquaporin genes based on drought stress tolerance in terms of growth and other yield related parameters. Similarly, they preferred TIP in contrast to previous studies in which PIP were mainly selected as candidates for the improvement of plant abiotic stress tolerance. They clearly demonstrated that plant overexpressing SITIP 2;2 adjusted whole plant transpiration regulation and relative water content under different abiotic stresses (Sade et al. 2009). Transgenic plants also exhibited increased transpiration under normal growth conditions, limited reduction of transpiration under drought and salt stresses and speed up the revival of transpiration upon recovery from these stresses. In conclusion, overexpression of the SITIP 2;2 extends the ability of the plant to maintain relatively normal physiological functions and also growth and yield even under severe stress conditions.

Similarly, Sade et al. (2010) suggested that tobacco stress-induced aquaporin gene $(N t A Q P 1)$ is involved in improving the tolerance of stress plants due to increased water use efficiency (WUE). Overexpression of NtAQP1 resulted in an increase of net photosynthetic rate, mesophyll $\mathrm{CO}_{2}$ conductance and stomatal conductance which collectively contributed towards enhanced stress tolerance in transgenic Arabidopsis and tomato plants under stress. This is also in agreement with previous 
reports which also suggested a role for $N t A Q P 1$ in photosynthesis and demonstrated that transgenic tobacco plants overexpressing $N t A Q P 1$ showed $20 \%$ increase in photosynthetic rate relative to controls while its antisense repression resulted in $13 \%$ decrease of it (Flexas et al. 2006).

Thus, the overexpression of different individual aquaporin genes might have opposite outcomes with respect to the response of the whole plant to abiotic stresses, emphasizing the importance of accurately selecting the right candidate aquaporin genes from this large and functionally variable family to improve plant response to various stresses. These results lead us to propose that there is a dire need to completely understand the roles and involvement of the aquaporins in the plant response to drought stress to bridge the gap in the existing knowledge base.

Table 1. Transgenic plants engineered for enhanced tolerance to drought stress.

\begin{tabular}{|c|c|c|c|}
\hline Gene & Species & Phenotype & Reference \\
\hline SiTIP2;2 & tomato & increase in osmotic water permeability and transpiration & Sade et al. 2009 \\
\hline CfPIP2;1 & Arabidopsis & better plant growth under dehydration stress & Jang et al. 2007 \\
\hline PgTIP1 & Arabidopsis & root dependent, drought and salt tolerance & Peng et al. 2007 \\
\hline PIP & soybean/lettuce & water conservation and drought tolerance & Porcel et al. 2006 \\
\hline$R W C 3$ & rice & maintenance of leaf water potential and transpiration under PEG stress & Lian et al., 2004 \\
\hline$P I P 1 b$ & tobacco & no increase in plant drought and salt stress tolerance & Aharon et al. 2003 \\
\hline PIP2:2 & Arabidopsis & increased root water uptake & Javot et al. 2003 \\
\hline NtAQP1 & tobacco & high root hydraulic conductance and drought tolerance & Siefritz et al. 2002 \\
\hline$L E A 4$ & tobacco & drought tolerance via stabilizing membrane and protein & Liu et al. 2009 \\
\hline OsLEA3 & rice & dehydration and salt stress tolerance & Hu et al. 2008 \\
\hline CaLEA6 & tobacco & protection of photosynthetic activity under drought & Jun et al. 2008 \\
\hline HVAl & mulberry & drought and salinity tolerance & Lal et al. 2008 \\
\hline Dehydrin & Arabidopsis & enhanced osmotic and salt stress tolerance & Brini et al. 2007 \\
\hline$H V A 1$ & creeping bentgrass & maintenance of high water contents in leaves under water stress & Fu et al. 2007 \\
\hline OsLEA3-1 & rice & drought resistance for yield in the field & Xiao et al. 2007 \\
\hline DQ663481 & tobacco & drought resistance via cell membrane stability & Wang et al. 2006 \\
\hline HVAl & wheat & improved plant water status and yield under field drought & Bahieldin et al. 2005 \\
\hline ME-leaN4 & lettuce & enhanced growth and delayed wilting under drought & Park et al. 2005a \\
\hline ME-leaN4 & Chinese cabbage & drought and salt resistance & Park et al. 2005b \\
\hline HVA1 & rice & dehydration avoidance and cell membrane stability & Babu et al. 2004 \\
\hline Rab 17 & Arabidopsis & enhanced osmotic stress tolerance & Figueras et al. 2004 \\
\hline CuCOR19 & tobacco & no effect on drought tolerance & Hara et al. 2003 \\
\hline CaLEA & Chinese cabbage & dehydration stress tolerance & Park et al. 2003 \\
\hline PF00477 & rice & enhanced dehydration tolerance & Cheng et al. 2002 \\
\hline HVA1 & oat & delayed wilting under drought stress & Maqbool et al. 2002 \\
\hline$L E A 3-L 2$ & wheat & increased content of protein of unknown function & Ndong et al. 2002 \\
\hline HVA1 & rice & drought and salinity tolerance & Rohila et al. 2002 \\
\hline$H V A 1$ & wheat & increased biomass and WUE under stress & Sivamani et al. 2000 \\
\hline RcHSP17.8 & Arabidopsis & increased drought, salt, heat and osmotic stress tolerance & Jiang et al. 2009 \\
\hline sHSP17.7 & rice & enhanced drought tolerance & Sato and Yokoya 2008 \\
\hline NtHSP70-1 & tobacco & drought tolerance due to regulated water flux & Cho and Hong 2006 \\
\hline AtHSP17.6A & Arabidopsis & increased tolerance to drought and salt stresses & Sun et al. 2001 \\
\hline
\end{tabular}

\section{Conclusions}

One purpose of studying abiotic stress responses in plants is to improve the abiotic stress tolerance of crops by means of genetic manipulation. Current state of knowledge has been improved by recent discoveries in engineering drought tolerance in plants. However, in naturally stress-tolerant plants, there is a wide variety of adaptations to stress, many of which have not yet been identified at the molecular level. Understanding the function of genes determining these properties will improve our understanding of the complexity of plant metabolism and may provide unique opportunities for the metabolic engineering. Commercially significant improving of crop performance under drought conditions has been challenging because of the complexity of the trait and the multitude of factors that influence yield. However, several crucial factors related to the plant response to drought stress have been identified and many of these factors have already been shown to be effective for engineering drought tolerance in model plants. The fact that many $L E A$ genes are simultaneously induced during stress indicates that LEA-type proteins co-operate during abiotic stresses. Because of this synergistic effect, 
ectopic expression of a single LEA-type protein is not always sufficient to confer plant tolerance, but Arabidopsis plants transformed with multiple LEA-type genes showed increased survival under freezing stress (Puhakainen et al. 2004). Such success under experimental conditions has encouraged the use of this approach to engineer drought tolerance in crop plants. To endow a plant with multiple stress resistance, cotransformation of multifunctional genes is possible. However, improvement of crops using the above strategies will require further research. Based on success, it is anticipated that transgenic plants conferring drought tolerance will eventually be released for field evaluation soon.

However, an understanding of the mechanistic basis for changes in plant gene expression in response to environmental cues is beginning to emerge. Similarly,

\section{References}

Abdeen, A., Schnell, J., Miki, B.: Transcriptome analysis reveals absence of unintended effects in drought-tolerant transgenic plants overexpressing the transcription factor ABF3. - BMC Genomics 11: 69, 2010.

Abe, H., Urao, T., Ito, T., Seki, M., Shinozaki, K., YamaguchiShinozaki, K.: Arabidopsis AtMYC2 (bHLH) and AtMYB2 (MYB) function as transcriptional activators in abscisic acid signaling. - Plant Cell 15: 63-78, 2003.

Agrawal, P.K., Jha, B.: Transcription factors in plants and ABA dependent and independent abiotic stress signaling. - Biol. Plant. 54: 201-212, 2010.

Aharon, R., Shahak, Y., Wininger, S., Bendov, R., Kapulnik, Y., Galili, G.: Overexpression of a plasma membrane aquaporin in transgenic tobacco improves plant vigor under favorable growth conditions but not under drought or salt stress. Plant Cell 15: 439-447, 2003.

Ahmad, R., Kim, M.D., Back, K.H., Kim, H.S., Lee, H.S., Kwon, S.Y., Murata, N., Chung, W.I.I., Kwak, S.S.: Stressinduced expression of choline oxidase in potato plant chloroplasts confers enhanced tolerance to oxidative, salt, and drought stresses. - Plant Cell Rep. 27: 687-698, 2008.

Alamillo, J., Almoguera, C., Bartels, D., Jordano, J.: Constitutive expression of small heat shock proteins in vegetative tissues of the resurrection plant Craterostigma plantagineum. - Plant mol. Biol. 29: 1093-1099, 1995.

Almoguera, C., Coca, M.A., Jordano, J.: Tissue-specific expression of sunflower heat shock proteins in response to water stress. - Plant J. 4: 947-958, 1993.

Babu, R.C., Zhang, J., Blum, A., Ho, T.H.D., Wu, R., Nguyen, H.T.: HVA1, a LEA gene from barley confers dehydration tolerance in transgenic rice (Oryza sativa L.) via cell membrane protection. - Plant Sci. 166: 855-862, 2004.

Bahieldin, A., Mahfouz, H.T., Eissa, H.F., Saleh, O.M., Ramadan, A.M., Ahmed, I.A., Dyer, W.E., El-Itriby, H.A., Madkour, M.A.: Field evaluation of transgenic wheat plants stably expressing the HVA1 gene for drought tolerance. Plant Physiol. 123: 421-427, 2005.

Baiges, I., Schaffner, A.R., Venzeller, M.J., Mas, A.: Plant aquaporins. - Physiol Plant. 115: 175-182, 2002.

Banzet, N., Richaud, C., Deveaux, Y., Kazmaier, M., Gagnon, J., Triantaphylides, C.: Accumulation of small heat shock proteins, including mitochondrial HSP22, induced by high throughput sequencing programs supported by genome-wide transcript profiling has a great potential in isolating differentially expressed and functionally important stress regulated genes. In a nutshell, in future, promises ushered by genomics, transcriptomics (Yoshida et al. 2008; Weston et al. 2008), proteomics (Bartels and Hussain 2008) or metabolomics (Rizhsky et al. 2004, Seki et al. 2007) could generate valuable information for engineering plants for their ultimate use in sustainable agriculture. Systems biology approaches relying on the integration of such "omics" based data will most certainly help to better understand the response of plants to abiotic stresses. However, a major challenge for the future will be to implement all the various data to engineer welladapted plants that produce the required high amount of biomass under both stress and non-stressed conditions.

oxidative stress and adaptive response in tomato cells. Plant J. 13: 519-527, 1998.

Bartels, D., Hussain, S.S.: Current status and implications of engineering drought tolerance in plants using transgenic approaches. - CAB Rev. 3: 20, 2008.

Bertrand, A., Paquin, R.: Influence of hardening temperature on frost tolerance of alfalfa and its sugar, starch and proline content. - Can. J. Plant Sci. 71: 737-747, 1991.

Bies-Etheve, N., Gaubier, P., Cooke, R., Raynal, M., Aspart, L., Delseny, M.: Late embryogenesis abundant (LEA) protein gene in Arabidopsis thaliana. - Seventh Int. Congr. Plant mol. Biol. 7: S03-S39, 2003.

Bohnert, H.J., Jensen R.G.: Strategies for engineering waterstress tolerance in plants. - Trends Biotechnol. 14: 89-97, 1996.

Bohnert, H.J., Shen B.: Transformation and compatible solutes. - Sci. Hort. 78: 237-260, 1999.

Bohnert, H.J., Sheveleva E.: Plant stress adaptations making metabolism move. - Curr. Opin. Plant Biol. 1: 267-274, 1998.

Boston, R.S., Viitanen, P.V., Vierling, E.: Molecular chaperones and protein folding in plants. - Plant mol. Biol. 32: 191-222, 1996.

Boursiac, Y., Chen, S., Luu, D.T., Sorieul, M., Van den Dries, N., Maurel, C.: Early effects of salinity on water transport in Arabidopsis roots. Molecular and cellular features of aquaporin expression. - Plant Physiol. 139: 790-805, 2005.

Boyer, J.S.: Plant productivity and environment. - Science 218: 443-448, 1982.

Bray, E.A., Bailey-Serres, J., Weretilnyk, E.: Responses to abiotic stresses. - In: Gruissem, W., Buchannan, B., Rockville, J.R. (ed.): Biochemistry and Molecular Biology of Plants. Pp. 1158-1249. American Society of Plant Physiologists, Rockville 2000.

Brini, F., Hanin, M., Lumbreras, V., Amara, I., Khoudi, H., Hassairi, A., Pages, M., Masmoudi, K.: Overexpression of wheat dehydrin DHN-5 enhances tolerance to salt and osmotic stress in Arabidopsis thaliana. - Plant Cell Rep. 26: 2017-2026, 2007.

Campbell, J.L., Klueva, N.Y., Zheng, H.G., Nieto-Sotelo, J, Ho, T.D., Nguyen, H.T.: Cloning of new members of heat shock protein HSP101 gene family in wheat (Triticum aestivum 
(L.) Moench) inducible by heat, dehydration, and ABA. Biochim. biophys. Acta 1517: 270-277, 2001.

Chang, P.F.L., Jinn, T.L., Huang, W.K., Chen, Y., Chang, H.M., Wang, C.W.: Induction of a cDNA clone from rice encoding a class II small heat shock protein by heat stress, mechanical injury, and salicylic acid. - Plant Sci. 172: 64-75, 2007.

Chang, Y.Y., Liu, H.C., Liu, N.Y., Hsu, F.C., Ko, S.S.: Arabidopsis Hsa32, a novel heat shock protein, is essential for acquired thermotolerance during long recovery after acclimation. - Plant Physiol. 140: 1297-1305, 2006.

Chaumont, F., Barrieu, F., Jung, R., Chrispeels, M.J.: Plasma membrane intrinsic proteins from maize cluster in two sequence subgroups with differential aquaporin activity. Plant Physiol. 122: 1025-1034, 2000.

Chaumont, F., Barrieu, F., Wojcik, E., Chrispeels, M.J., Jung, R.: Aquaporins constitute a large and highly divergent protein family in maize. - Plant Physiol. 125: 1206-1215, 2001.

Chen, J.B., Wang, S.M., Jing, R.L., Mao, X.G.: Cloning the PvP5CS gene from common bean (Phaseolus vulgaris) and its expression patterns under abiotic stresses. - J. Plant Physiol. 166: 12-19, 2009.

Chen, T.H., Murata, N.: Enhancement of tolerance of abiotic stress by metabolic engineering of betaines and other compatible solutes. - Curr. Opin. Plant Biol. 5: 250-257, 2002.

Cheng, W.H., Endo, A., Zhou, L., Penny, J., Chen, H.C., Arroyo, A., Leon, P., Nambara, E., Asami, T., Seo, M.: A unique short-chain dehydrogenase/reductase in Arabidopsis glucose signaling and abscisic acid biosynthesis and functions. - Plant Cell 14: 2723-2743, 2002.

Cho, E.K., Hong, C.B.: Over-expression of tobacco NtHSP70-1 contributes to drought-stress tolerance in plants. - Plant Cell Rep. 25: 349-358, 2006.

Chrispeels, M.J., Agre, P.: Aquaporins: water channel proteins of plant and animal cells. - Trends Biochem. Sci. 19: 421425, 1994.

Close, T.J.: Dehydrins: emergence of a biochemical role of a family of plant dehydration proteins. - Plant Physiol. 97: 795-803, 1996.

Cortina, C., Culianez-Macia, F.: Tomato abiotic stress enhanced tolerance by trehalose synthesis. - Plant Sci. 169: 75-82, 2005.

Crowe, J.H., Carpenter, J.F., Crowe, L.M.: The role of vitrification in anhydrobiosis. - Annu. Rev. Plant Physiol. Plant mol.Biol. 60: 73-103, 1998.

Dalal, M., Tayal, D., Chinnusamy, V., Bansala, K.C.: Abiotic stress and ABA-inducible group 4 LEA from Brassica napus plays a key role in salt and drought tolerance. - J. Biotechnol. 139: 137-145, 2009.

Danielson, J.A.H., Johanson, U.: Unexpected complexity of the aquaporin gene family in the moss Physcomitrella patens. BMC Plant Biol. 8: 45, 2008.

Delauney, A.J., Verma, D.P.S.: Proline biosynthesis and osmoregulation in plants. - Plant J. 4: 215-223, 1993.

Dubouzet, J.G., Sakuma, Y., Ito, Y., Kasuga, M., Dubouzet, E.G., Miura, S., Seki, M., Shinozaki, K., YamaguchiShinozaki, K.: OsDREB genes in rice (Oryza sativa L.) encode transcription activators that function in drought, high salt and cold responsive gene expression. - Plant J. 33: 751-763, 2003.

Dure, L., III.: A repeating 11-mer amino acid motif and plant desiccation. - Plant J. 3: 363-369, 1993 a.

Dure, L., III. Structural motifs in LEA proteins. - In: Close, T.J.,
Bray, E.A. (ed.): Plant Responses to Cellular Dehydration during Environmental Stress. Pp. 91-103. American Society of Plant Physiologists, location 1993b.

Ehrnsperger, M., Graber, S., Gaestel, M., Buchner, J.: Binding of non-native protein to Hsp25 during heat shock creates a reservoir of folding intermediates for reactivation. - EMBO J. 16: 221-229, 1997.

Ermawati, N., Liang,Y.S., Cha, J.Y., Shin, D., Jung, M.H., Lee, J.J., Lee, B.H., Han, D., Lee, K.H., Son, D.: A new tip homolog, ShTIP, from Salicornia shows a different involvement in salt stress compared to that of TIP from Arabidopsis. - Biol. Plant. 53: 271-277, 2009.

Figueras, M., Pujal, J., Saleh, A., Save, R., Pages, M., Goday, A.: Maize Rab17 overexpression in Arabidopsis plants promotes osmotic stress tolerance. - Ann. appl. Biol. 144: 251-257, 2004

Flexas, J., Ribas-Carbo, M., Hanson, D.T., Bota, J., Otto, B., Cifre, J., McDowell, N., Medran, O.H., Kaldenhoff, R.: Tobacco aquaporin NtAQP1 is involved in mesophyll conductance to $\mathrm{CO}_{2}$ in vivo. - Plant J. 48: 427-439, 2006.

Fu, D., Huang, B., Xiao, Y., Muthukrishnan, S., Liang, G.H.: Overexpression of barley hval gene in creeping bentgrass for improving drought tolerance. - Plant Cell Rep. 26: 467477, 2007.

Galau, G.A., Wang, H.Y.C., Hughes, D.W.: Cotton Lea5 and Lea14 encode atypical late embryogenesis abundant proteins. - Plant Physiol. 101: 695-696, 1993.

Garay-Arroyo, A., Colmenero-Flores, J.M., Garciarrubio, A., Covarrubias, A.A.: Highly hydrophilic proteins $n$ prokaryotes and eukaryotes are common during conditions of water deficit. - J. biol. Chem. 275: 5668-5674, 2000.

Gilmour, S.J., Sebolt, A.M., Salazar, M.P., Everard, J.D., Thomashow, M.F.: Overexpression of the Arabidopsis CBF3 transcriptional activator mimics multiple biochemical changes associated with cold acclimation. - Plant Physiol. 124: 1854-1865, 2000.

Goddijn, O.J.M., Van Dun, K.: Trehalose metabolism in plants. -Trends Plant Sci. 4: 315-319, 1999.

Goyal, K., Walton, L.J., Tunnaclive, A.: LEA proteins prevent protein aggregation due to water stress. - J. Biochem. 388: $151-157,2005$.

Grelet, J., Benamar, A., Teyssier, E., Avelange-Macherel, M.H., Grunwald, D., Macherel, D.: Identification in pea seed mitochondria of a late-embryogenesis abundant protein able to protect enzymes from drying. - Plant Physiol. 137: 157$167,2005$.

Guan, J.C., Jinn, T.L., Yeh, C.H., Feng, S.P., Chen, Y.M., Lin, C.Y.: Characterization of the genomic structures and selective expression profiles of nine class I small heat shock protein genes clustered on two chromosomes in rice (Oryza sativa L.). - Plant mol. Biol. 56: 795-809, 2004.

Gubiš, J., Vaňková, R., Červená, V., Dragúňová ${ }_{2}$ M.M., Hudcovicová, M., Lichtnerová, H.T., Dokupil, T., Jureková, Z.: Transformed tobacco plants with increased tolerance to drought. - South Afr. J. Bot. 73: 505-511, 2007.

Gupta, A.B., Sankararamakrishnan, R.: Genome-wide analysis of major intrinsic proteins in the tree plant Populus trichocarpa: characterization of XIP subfamily of aquaporins from evolutionary perspective. - BMC Plant Biol. 9: 134, 2009.

Hachez, C., Zelazny, E., Chaumont, F.: Modulating the expression of aquaporin genes in planta: a key to understand their physiological functions. - Biochim. biophys. Acta 1758: 1142-1156, 2006.

Hamilton, E.W., Heckathorn, S.A.: Mitochondrial adaptations 
to $\mathrm{NaCl}$ : complex I is protected by anti-oxidants and small heat shock proteins, whereas complex II is protected by proline and betaine. - Plant Physiol. 126: 1266-1274, 2001.

Hara, M., Terashima, S., Fukaya, T. Kuboi, T.: Enhancement of cold tolerance and inhibition of lipid peroxidation by citrus dehydrin in transgenic tobacco. - Planta 217: 290-298, 2003.

Harrington, H.M., Alm, D.M.: Interaction of heat and salt shock in cultured tobacco cells. - Plant Physiol. 88: 618-625, 1988.

Härndahl, U., Hall, R.B., Osteryoung, K.W., Vierling, E., Bornman, J.F., Sundby, C.: The chloroplast small heat shock protein undergoes oxidation-dependent conformational changes and may protect plants from oxidative stress. - Cell Stress Chaperones 4: 129-138, 1999.

Hartl, F.U.: Molecular chaperones in cellular protein folding. Nature 381: 571-579, 1996.

Haslbeck, M., Walke, S., Stromer, T., Ehrnsperger, M., White, H.E., Chen, S., Saibil, H.R., Buchner, J.: Hsp26: a temperature regulated chaperone. - EMBO J. 18: 6744-6751, 1999.

Hendrick, J.P., Hartl, F.U.: Molecular chaperone functions of heat-shock proteins. - Annu. Rev. Biochem. 62: 349-384, 1993.

Hoekstra, F.A., Golovina, E.A., Buitink, J.: Mechanisms of plant desiccation tolerance. - Trends Plant Sci. 6: 431-438, 2001.

Hook, D.W.A., Harding, J.J.: Protection of enzymes by $\alpha$ crystallin acting as a molecular chaperone. - Int. J. Biol. Macromol. 22: 295-306, 1998.

Horwitz, J.: $\alpha$-Crystallin can function as a molecular chaperone. - Proc. nat. Acad. Sci. USA 89: 10449-10453, 1992.

Hsieh, T.H., Lee, J.T., Yang, P.T., Chiu, L.H., Charng, Y.Y., Wang, Y.C., Chan, M.T.: Heterology expression of the Arabidopsis c-repeat/dehydration response element binding factor 1 gene confers elevated tolerance to chilling and oxidative stresses in transgenic tomato. - Plant Physiol. 129: 1086-1094, 2002.

Hu, H., You, J., Fang, Y., Zhu, X., Qi, Z., Xiong, L.: Characterization of transcription factor gene SNAC2 conferring cold and salt tolerance in rice. - Plant mol. Biol. 67:169-181, 2008.

Hu, W.H., Hu, G.C., Ban, B.: Genome-wide survey and expression profiling of heat shock proteins and heat shock factors revealed overlapped and stress specific response under abiotic stresses in rice. - Plant Sci. 176: 583-590, 2009.

Hu, X.J., Zhang, Z.B., Xu, P., Fu, Z.Y., Hu, S.B., Song, W.Y.: Multifunctional genes: the cross talk among the regulation networks of abiotic stress responses. - Biol. Plant. 54: 213223, 2010.

Hussain, S.S., Ali, M., Maqbool, A., Siddique, K.H.M.: Polyamines: natural and engineered abiotic and biotic stress tolerance in plants. - Biotechnol. Adv. 29: 300-311, 2011 a.

Hussain, S.S., Kayani, M.A., Amjad, M.: Transcription factors as tools to engineer enhanced drought stress tolerance in plants. - Biotechnol. Progr. 27: 297-306, 2011 b.

Ingram, J., Bartels, D.: The molecular basis of dehydration tolerance in plants. - Annu. Rev. Plant Biol. 47: 377-403, 1996.

Ito, Y., Katsura, K., Maruyama, K., Taji, T., Kobayashi, M., Seki, S., Shinozaki, K., Yamaguchi-Shinozaki, K.: Functional analysis of rice DREB1/CBF type transcription factors involved in cold responsive gene expression in transgenic rice. - Plant Cell Physiol. 47: 141-153, 2006.

Iturriaga, G., Schneider, K., Salamini, F., Bartels, D.: Expression of desiccation-related proteins from the resurrection plant in transgenic tobacco. - Plant mol. Biol. 20: 555-558, 1992.

Iturriaga, G., Gaff, G.F., Zentella, R.: New desiccation tolerant plants, including a grass in the central highlands of Mexico, accumulate trehalose. - Aust. J. Bot. 48: 153-158, 2000.

Jain, R.K., Selvaraj, G.: Molecular genetic improvement of salt tolerance in plants. - Annu. Rev. Biotechnol. 3: 245-267, 1997.

Jang, J.Y., Lee, S.H., Rhee, J.Y., Chung, G.C., Ahn, S.J., Kang, H.: Transgenic Arabidopsis and tobacco plants overexpressing an aquaporin respond differently to various abiotic stresses. - Plant mol. Biol. 64: 621-632, 2007.

Javot, H., Lauvergeat, V., Santoni, V., Laurent, M.F., Guclu, J., Vinh, J., Heyes, J., Franck, K.I., Schaffner, A.R., Bouchez, D., Maurel, C.: Role of a single aquaporin isoform in root water uptake. - Plant Cell 15: 509-522, 2003.

Jiang, C., Xu, J., Zhang, H., Zhang, X., Shi, J., Li, M., Ming, F.: Acytosolic class I small heat shock protein, RcHSP17.8, of Rosa chinensis confers resistance to a variety of stresses to Escherichia coli, yeast and Arabidopsis thaliana. - Plant Cell Environ. 32: 1046-1059, 2009.

Jinn, T.L., Chen, Y.M., Lin, C.Y.: Characterization and physiological function of class 1 low molecular weight heat shock protein complexes in soybean. - Plant Physiol. 108: 693-701, 1995.

Johanson, U., Karlsson, M., Johansson, I., Gustavsson, S., Sjovall, S., Fraysse, L., Weig, A.R., Kjellbom, P.: The complete set of genes encoding major intrinsic proteins in Arabidopsis provides a framework for a new nomenclature for major intrinsic proteins in plants. - Plant Physiol. 126: 1358-1369, 2001.

Johnson, K.D., Höfte, H., Chrispeels, M.J.: An intrinsic tonoplast protein of protein storage vacuoles in seeds is structurally related to a bacterial solute transporter $(\mathrm{GlpF})$. Plant Cell 2: 525-532, 1990.

Jun, S.S., Choi, H.J., Lee, H.Y., Hong, Y.N.: Differential protection of photosynthetic capacity in trehalose and LEA protein producing transgenic plants under abiotic stresses. J. Plant Biol. 51: 327-336, 2008.

Jung, C., Seo, J.S., Han, S.W., Koo, Y.J., Kim, C.H., Song, S.I., Nahm, B.H., Choi, Y.D., Cheong, J.J.: Overexpression of AtMYB44 enhances stomatal closure to confer abiotic stress tolerance in transgenic Arabidopsis. - Plant Physiol. 146: 623-635, 2008.

Jyothsnakumari, G., Thippeswamy, M., Veeranagamallaiah, G., Sudhakar, C.: Differential expression of LEA proteins in two genotypes of mulberry under salinity. - Biol. Plant. 53: 145-150, 2009.

Karim, S., Aronsson, H., Ericson, H., Pirhonen, M., Leyman, B., Welin, B., Mantyla, E., Palva, E.T., Van Dijck, P., Holstrom, K.O.: Improved drought tolerance without undesired side effects in transgenic plants producing trehalose. - Plant mol. Biol. 64: 371-386, 2007.

Kathuria, H., Giri, J., Tyagi, H., Tyagi, A.K.: Advances in transgenic rice biotechnology. - Crit. Rev. Plant Sci. 26: 65103, 2007.

Katsuhara, M., Koshio, K., Shibasaka, M., Hayashi, Y., Hayakawa, T., Kasamo, K.: Over-expression of a barley aquaporin increased the shoot/root ratio and raised salt sensitivity in transgenic rice plants. - Plant Cell Physiol. 44: 1378-1383, 2003.

Kotak, S., Larkindale, J., Lee, U., Von Koskull-Doring, P., Vierling, E., Scharf, K.D.: Complexity of the heat stress response in plants. - Curr. Opin. Plant Biol. 10: 310-316, 2007. 
Kumar, V., Shriram, V., Kavi-Kishor, P.B., Jawali, N., Shitole, M.G.: Enhanced praline accumulation and salt stress tolerance of transgenic indica rice by overexpressing P5CSF129A gene. - Plant Biotechnol. Rep. 4: 37-48, 2010.

Lal, S., Gulyani, V., Khurana, P.: Overexpression of HVA1 gene from barley generates tolerance to salinity and water stress in transgenic mulberry (Morus indica). - Transgenic Res. 17: 651-663, 2008

Lee, B.H., Won, S.H., Lee, H.S., Miyao, M., Chung, W.I., Kim I.J., Jo, J.: Expression of the chloroplast-localized small heat shock protein by oxidative stress in rice. - Gene 245: 283290, 2000.

Lee, G.J., Pokala, N., Vierling, E.: Structure and in vitro molecular chaperone activity of cytosolic small heat shock proteins from pea. - J. biol. Chem. 270: 10432-10438, 1995.

Lee, G.J., Roseman, A.M., Saibil, H.R., Vierling, E.: A small heat shock protein stably binds heat-denatured model substrates and can maintain a substrate in a foldingcompetent state. - EMBO J. 3: 659-671, 1997.

Lian, H.L., Yu, X., Ye, Q., Ding, X.S., Kitagawa, Y., Kwak, S.S., Su, W.A., Tang, Z.C.: The role of aquaporin RWC3 in drought avoidance in rice. - Plant Cell Physiol. 45: 481-489, 2004.

Liang, C.Y., Xi, Y., Shu, J., Li, J., Yang, J.L., Che, K.P., Jin, D.M., Liu, X.L., Weng, M.L., He, Y.K., Wang, B.: Construction of a BAC library of Physcomitrella patens and isolation of a LEA gene. - Plant Sci. 167: 491-498, 2004.

Liu, J.H., Nada, K., Honda, C., Kitashiba, H., Wen, X.P., Pang, X.M., Moriguchi, T.: Polyamine biosynthesis of apple callus under salt stress: importance of arginine decarboxylase pathway in stress response. - J. exp. Bot. 57: 2589-2599, 2006

Liu, R., Liu, M., Liu, J., Chen, Y., Chen, Y., Lu, C.: Heterologus expression of a Ammopiptanthus mongolicus late embryogenesis abundant protein gene (AmLEA) enhances Escherichia coli viability under cold and heat stress. - Plant Growth Regul. 60: 163-168, 2010.

Liu, X., Wang, Z., Wang, L.L., Wu, R.H., Phillips, J., Deng, X.: LEA 4 group genes from the resurrection plant Boea hygrometrica confer dehydration tolerance in transgenic tobacco. - Plant Sci. 176: 90-98, 2009.

Livingston, D.P.,III., Hincha, D.K., Heyer, A.G.: Fructan and its relationship to abiotic stress tolerance in plants. - Cell Mol. Life Sci. 66: 2007-2023, 2009.

Lopez-Matas, M.A., Nunez, P., Soto, A., Allona, I., Casado, R., Collada, C., Guevara, M.A., Aragoncillo, C., Gomez, L.: Protein cryoprotective activity of a cytosolic small heat shock protein that accumulates constitutively in chestnut stems and is up-regulated by low and high temperatures. Plant Physiol. 134: 1708-1717, 2004.

Low, D., Brandle, K., Nover, L., Forreiter, C.: Cytosolic heatstress proteins Hsp17.7 class I and Hsp17.3 class II of tomato act as molecular chaperones in vivo. - Planta 211: 575-582, 2000 .

Luu, D.T., Maurel, C.: Aquaporins in a challenging environment: molecular gears for adjusting plant water status. - Plant Cell Environ. 28: 85-96, 2005.

Lv, S., Yang, A., Zhang, K., Wang, L., Zhnag, J.: Increase of glycinebetaine synthesis improves drought tolerance in cotton. - Mol. Breed. 20: 233-248, 2007.

Ma, C., Haslbeck, M., Babujee, L., Jahn, O., Reumann, S.: Identification and characterization of a stress-inducible and a constitutive small heat-shock protein targeted to the matrix of plant peroxisomes. - Plant Physiol. 141: 47-60, 2006.
Malik, M.K., Slovin, J.P., Hwang, C.H., Zimmerman, J.L.: Modified expression of a carrot small heat shock protein gene, hsp17.7, results in increased or decreased thermo tolerance double danger. - Plant J. 20: 89-99, 1999.

Mamedov, T.G., Shono, M.: Molecular chaperone activity of tomato (Lycopersicon esculentum) endoplasmic reticulumlocated small heat shock protein. - J. Plant Res. 121: 235243, 2008.

Mani, S., Van de Cotte, B., Montagu, M., Verbruggen, N.: Altered levels of proline dehydrogenase cause hypersensitivity to proline and its analogs in Arabidopsis. Plant Physiol. 128: 73-83, 2002.

Maqbool, B., Zhong, H., El-Maghraby, Y., Ahmad, A., Chai, B. Wang, W., Sabzikar, R., Sticklen, B.: Competence of oat (Avena sativa L.) shoots apical meristems for integrative transformation, inherited expression, and osmotic tolerance of transgenic lines containing hval. - Theor. appl. Genet. 105: 201-208, 2002.

Marini, I., Moschini, R., Corso, A.D., Mura, U.: Complete protection by $\alpha$-crystallin of lens sorbitol dehydrogenase undergoing thermal stress. - J. biol. Chem. 275: 32559$32565,2000$.

Martre, P., Morillon, R., Barrieu, F., North, G.B., Nobel, P.S., Chrispeels, M.J.: Plasma membrane aquaporins play a significant role during recovery from water deficit. - Plant Physiol. 130: 2101-2110, 2002.

Maurel, C., Javot, H., Lauvergeat, V., Gerbeau, P., Tournaire, C., Santoni, V., Heyes, J.: Molecular physiology of aquaporins in plants. - Int. Rev. Cytol. 215: 105-148, 2002.

Maurel, C., Tacnet, F., Guclu, J., Guern, J., Ripoche, P.: Purified vesicles of tobacco cell vacuolar and plasma membranes exhibit dramatically different water permeability and water channel activity. - Proc. nat. Acad. Sci. USA 94: 7103-7108, 1997.

McCue, K.F., Hanson, A.D.: Drought and salt tolerance: toward understanding and application. - Trends Biotechnol. 8: 35862, 1990.

McNeil, S.D., Nuccio, M.L., Hanson, A.D.: Betaines and related osmoprotectants. Targets for metabolic engineering of stress resistance. - Plant Physiol. 120: 945-949, 1999.

Miranda, J.A., Avonce, N., Suarez, R., Thevelein, J.M., Dijck, P.V., Iturriaga, G.: A bifunctional TPS-TPP enzyme from yeast confers tolerance to multiple and extreme abiotic conditions in transgenic Arabidopsis. - Planta 226: 14111421, 2007.

Moons, A., De Keyser, A., Van Montagu, M.: A group 3 LEA cDNA of rice, responsive to abscisic acid, but not to jasmonic acid, shows variety-specific differences in salt stress response. - Gene 191: 197-204, 1997.

Muchowski, P.J., Clark, J.I.: ATP-enhance molecular chaperone functions of the small heat shock protein human $\alpha B$ crystallin. - Biochemistry 95: 1004-1009, 1998.

Murakami, T., Matsuba, S., Funatsuki, H., Kawaguchi, K., Saruyama, H., Tanida, M., Sato, Y.: Over-expression of a small heat shock protein, sHSP17.7, confers both heat tolerance and UV-B resistance to rice plants. - Mol. Breed. 13: $165-175,2004$.

Murelli, C., Rizza, F., Marinone, A., Dulio, A., Terzi, V., Cattivelli, L.: Metabolic changes associated with coldacclimation in contrasting cultivars of barley. - Plant Physiol. 94: 87-93, 1995.

Naidu, B.P., Paleg, L.G., Aspinall, D., Jennings, A.C., Jones, G.P.: Amino acid and glycine betaine accumulation in coldstressed wheat seedlings. - Phytochemistry 30: 407-409, 1991. 
Nakashima, K., Tran, L.S., Van Nyugen, D., Fujita, M., Maruyama, K., Todaka, D., Ito, Y., Hayashi, N., Shinozaki, K., Yamaguchi-Shinozaki, K.: Functional analysis of a NAC-type transcription factor OsNAC6 involved in abiotic and biotic stress-responsive gene expression in rice. - Plant J. 51: 617-630, 2007

Ndong, C., Danyluk, J., Wilson, K.E., Pocock, T., Huner, N.P.A., Sarhan, F.: Cold-regulated cereal chloroplast late embryogenesis abundant-like proteins. Molecular characterization and functional analyses. - Plant Physiol. 129: 1368-1381, 2002.

Neta-Sharir, I., Isaacson, T., Lurie, S., Weiss, D.: Dual role for tomato heat shock protein 21: protecting photosystem II from oxidative stress and promoting color changes during fruit maturation. - Plant Cell 17: 1829-1838, 2005.

Nomura, M., Muramoto, Y., Yasuda, S., Takabe, T., Kishitani S.: The accumulation of glycinebetaine during cold acclimation in early and late cultivars of barley. - Euphytica 83: 247-250, 1995.

Nuccio, M.L., Rhodes, D., McNeil, S.D., Hanson, A.D.: Metabolic engineering of plants for osmotic stress resistance. - Curr. Opin. Plant Biol. 2: 128-134, 1999.

Oh, S.J., Song, S.I., Kim, Y.S., Jang, H.J., Kim, M., Kim, Y.K.: Arabidopsis CBF3/DREB1A and ABF3 in transgenic rice increased tolerance to abiotic stress without stunting growth. - Plant Physiol. 138: 341-351, 2005.

Oraby, H.F., Ransom, C.B., Kravchenko, A.N., Sticklen, M.B.: Barley HVA1 gene confers salt tolerance in $R 3$ transgenic oat. - Crop Sci. 45: 2218-2227, 2005.

Ouyang, S., Zhu, W., Hamilton, J., Lin, H., Campbell, M., Childs, K., Thibaud-Nissen, F., Malek, R.L., Lee, Y., Zheng, L., Orvis, J., Haas, B., Wortman, J., Buell, C.R.: The TIGR rice genome annotation resource: improvements and new features. - Nucl. Acids Res. 35 (Suppl.): D883-D887, 2007.

Pareek, A., Singla, S.L., Grover, A.: Evidence for accumulation of a $55 \mathrm{kDa}$ stress-related protein in rice and several other plant genera. - Plant Sci. 134: 191-197, 1998.

Park, B.J., Liu, Z., Kanno, A., Kameya, T.: Increased tolerance to salt- and water-deficit stress in transgenic lettuce (Lactuca sativa L.) by constitutive expression of LEA. Plant Growth Regul. 45: 165-171, 2005a.

Park, B.J., Liu, Z., Kanno, A., Kameya, T.: Genetic improvement of Chinese cabbage for salt and drought tolerance by constitutive expression of a $B$. napus LEA gene. - Plant Sci. 169: 553-558, 2005 b.

Park, E.J., Jeknic, Z., Pino, M.T., Murata, N., Chen, T.H.H.: Glycine betaine accumulation is more effective in chloroplasts than in the cytosol for protecting transgenic tomato plants against abiotic stress. - Plant Cell Environ. 30: 994-1005. 2007.

Park, E.J., Jeknic, Z., Sakamoto, A., Denoma, Y., Yawansiri, R., Murata, N., Chen, T.H.H.: Genetic engineering of glycine betaine synthesis in tomato protects seeds, plants, and flowers from chilling damage. - Plant J. 40: 474-487, 2004.

Park, S.H., Jun, S.S., An, G., Hong, Y.N., Park, M.C.: A comparative study on the protective role of trehalose and LEA proteins against abiotic stresses in transgenic Chinese cabbage (Brassica campestris) overexpressing CaLEA or OtsA. - J. Plant Biol. 46: 277-286, 2003.

Paul, J.M., Primavesi, L.F., Jhurreea, D., Zhang, Y.: Trehalose metabolism and signaling. - Annu. Rev. Plant Biol. 59: 417441, 2008.

Pellegrineschi, A., Reynolds, M., Pacheco, M., Brito, R.M., Almeraya, R., Yamaguchi-Shinozaki, K., Hoisington, D.: Stress induced expression in wheat of the Arabidopsis thaliana DREB1A gene delays water stress symptoms under greenhouse conditions. - Genome 47: 493-500, 2004.

Peng, Y., Lin, W., Cai, W., Arora, R.: Overexpression of a Panax ginseng tonoplast aquaporin alters salt tolerance, drought tolerance and cold acclimation ability in transgenic Arabidopsis plants. - Planta 226: 729-740, 2007.

Pilon-Smits, E.A.H., Ebskamp, M.J.M., Paul, M.J., Jeuken, M.J.W., Weisbeek, P.J., Smeekens, S.C.M.: Improved performance of transgenic fructan-accumulating tobacco under drought stress. - Plant Physiol. 107: 125-130, 1995.

Porcel, R., Aroca, R., Rosario, A., Ruiz-Lozano, J.M.: PIP Aquaporin gene expression in arbuscular mycorrhizal Glycine max and Lactuca sativa plants in relation to drought stress tolerance. - Plant mol. Biol. 60: 389-404, 2006.

Puhakainen, T., Hess, M.W., Makela, P., Svensson, J., Heino, P., Palva, E.T.: overexpression of multiple dehydrin genes enhances tolerance to freezing stress in Arabidopsis. - Plant mol. Biol. 54: 743-753, 2004.

Qiu, Y., Yu, D.: Over-expression of the stress-induced OsWRKY45 enhances disease resistance and drought tolerance in Arabidopsis. - Environ. exp. Bot. 65: 35-47, 2009.

Quan, R., Shang, M., Zhang, H., Zhao, Y., Zhang, J.: Engineering of enhanced glycine betaine synthesis improves drought tolerance in maize. - Plant Biotechnol. J. 2: 477-486, 2004.

Quigley, F., Rosenberg, J.M., Shachar-Hill, Y., Bohnert, H.J.: From genome to function: the Arabidopsis aquaporins. Genome Biol. 3: 1-17, 2002.

Raynal, M., Gaubier, P., Grellet, F., Delseny, M.: Nucleotide sequence of a radish cDNA clone coding for a late embryogenesis abundant (LEA) protein. - Nucl. Acids Res. 18: 6132, 1990.

Rizhsky, L., Liang, H., Shuman, J., Shulaev, V., Davletova, S., Mittler, R.: When defense pathways collide. The response of Arabidopsis to a combination of drought and heat stress. Plant Physiol. 134: 1683-1696, 2004.

Rohilla, J.S., Jain, R.K., Wy, R.: Genetic improvement of Basmati rice for salt and drought tolerance by regulated expression of a barley Hval cDNA. - Plant Sci. 163: 525532, 2002.

Roychoudhury, A., Roy, C., Sengupta, D.N.: Transgenic tobacco plants overexpressing the heterologous LEA gene Rab16A from rice during high salt and water deficit display enhanced tolerance to salinity stress. - Plant Cell Rep. 26: 1839-1859, 2007.

Sade, N., Gebretsadik, M., Seligmann, R., Schwartz, A., Wallach, R., Moshelion, M.: The role of tobacco aquaporin1 in improving water use efficiency, hydraulic conductivity and yield production under salt stress. - Plant Physiol. 152: 245-254, 2010.

Sade, N., Vinocur, B.J., Diber, A., Shatil, A., Nissan, H., Wallach, R., Karchi, H., Moshelion, M.: Improving plant stress tolerance and yield production: is the tonoplast aquaporin SITIP2;2 a key to isohydric to anisohydric conversion. - New Phytol. 181: 651-661, 2009.

Sakurai, J., Ishikawa, F., Yamaguchi, T., Uemura, M., Maeshima, M.: Identification of 33 rice aquaporin genes and analysis of their expression and function. - Plant Cell Physiol. 46: 1568-1577. 2005.

Sanmiya, K., Suzuki, K., Egawa, Y. Shono, M.: Mitochondrial small heat-shock protein enhances thermotolerance in tobacco plants. - FEBS Lett. 557: 265-268, 2004.

Sato, Y., Murakami, T., Funatsuki, H., Matsuba, S., Saruyama, H., Tanida, M.: Heat shock-mediated APX gene expression 
and protection against chilling injury in rice seedlings. - J. exp. Bot. 52: 145-151, 2001.

Sato, Y., Yokoya, S.: Enhanced tolerance to drought in transgenic rice plants overexpressing a small heat-shock protein, sHSP17.7. - Plant Cell Rep. 27: 329-334, 2008.

Schaeffner, A.R.: Aquaporin function, structure, and expression: are there more surprises to surface in water relations? - Planta 204: 131-139, 1998.

Schwechheimer, C., Zourelidou, M., Bevan, M.W.: Plant transcription factor studies. - Annu. Rev. Plant Physiol. Plant mol. Biol. 49: 127-150, 1998.

Sebehat, A., Lurie, S., Weiss, D.: Expression of small heatshock proteins at low temperatures. - Plant Physiol. 117: 651-658, 1998.

Sebehat, A., Weiss, D., Lurie, S.: The correlation between heat shock protein accumulation and persistence and chilling tolerance in tomato fruits. - Plant Physiol. 110: 531-537, 1996.

Seki, M., Narusaka, M., Abe, M., Kasuga, M., YamaguchiShinozaki, K., Carninci, P., Hayashizaki, Y., Shinozaki, K.: Monitoring the expression pattern of 1300 Arabidopsis under drought and cold stresses by using a full length cDNA microarray. - Plant Cell 13: 62-72, 2001.

Seki, M., Umezawa, T., Urano, K., Shinozaki, K.: Regulatory metabolic networks in drought stress responses. - Curr. Opin. Plant Biol. 10: 296-302, 2007.

Serraj, R., Sinclair, T.R.: Osmolyte accumulation: can it really help increase crop yield under drought conditions? - Plant Cell Environ. 25: 333-341, 2002.

Sheveleva, E.V., Chmara, W., Bohnert, H.J., Jensen, R.G.: Increased salt and drought tolerance by D-ononitol production in transgenic Nicotiana tabacum L. - Plant Physiol. 115: 1211-1219, 1997.

Sheveleva, E.V., Marquez, S., Chmara, W., Zegeer, A., Jensen R.G, Bohnert, H.J.: Sorbitol-6-phosphate dehydrogenase expression in transgenic tobacco. High amounts of sorbitol lead to necrotic lesions. - Plant Physiol. 117: 831-839, 1998.

Shih, M.D., Lin, S.C., Hsieh, J.S., Tsou, C.H., Chow, T.Y., Lin, T.P., Hsing, Y.I.C.: Gene cloning and characterization of a soybean (Glycine max L.) LEA protein, GmPM16. - Plant mol. Biol. 56: 689-703, 2004.

Shinozaki, K., Yamaguchi-Shinozaki, K.: Molecular response to dehydration and low temperature: differences and cross-talk between two stress signaling pathways. - Curr. Opin. Plant Biol. 3: 217-223, 2000.

Shinozaki, K., Yamaguchi-Shinozaki, K., Seki, M.: Regulatory network of gene expression in the drought and cold stress responses. - Curr. Opin. Plant Biol. 6: 410-417, 2003.

Siddique, M., Gernhard, S., von Koskull-Doring, P., Vierling, E., Scharf, K.D.: The plant sHSP superfamily: five new members in Arabidopsis thaliana with unexpected properties. - Cell Stress Chaperones 13: 183-197, 2008.

Siefritz, F., Tyree, M.T., Lovisolo, C., Schubert, A., Kaldenho, V.R.: PIP1 plasma membrane aquaporins in tobacco: from cellular effects to function in plants. - Plant Cell 14: 869876, 2002.

Simon-Sarkadi, L., Kocsy, G., Varhegyi, A., Galiba, G., De Ronde, J.A.: Genetic manipulation of proline accumulation influences the concentrations of other amino acids in soybean subjected to simultaneous drought and heat stress. J. Agr. Food Chem. 53: 7512-7517, 2005.

Singh, K., Foley, R.C., Oñate-Sánchez, L.: Transcription factors in plant defense and stress responses. - Curr. Opin. Plant Biol. 5: 430-436, 2002.

Sivamani, E., Bahieldin, A., Wraith, J.M., Al-Niemi, T., Dyer,
D.E., Ho, T.H.D., Qu, R.: Improved biomass productivity and water use efficiency under water deficit conditions in transgenic wheat constitutively expressing the barley HVAI gene. - Plant Sci. 155: 1-9, 2000.

Smart, L.B., Moskal, W.A., Cameron, K.D., Bennett, A.B.: MIP genes are down-regulated under drought stress in Nicotiana glauca. - Plant Cell Physiol. 42: 686-693, 2001.

Smýkal, P., Mašín, J., Hardy, I., Konopásek, I., Žárský, V.: Chaperone activity of tobacco HSP18, a small heat-shock protein is inhibited by ATP. - Plant J. 23: 703-713, 2000.

Sørensen, J.G., Kristensen, T.N., Loeschcke, V.: The evolutionary and ecological role of heat shock proteins. Ecol Lett. 6: 1025-37, 2003.

Sreenivasulu, N., Sopory, S.K., Kavi-Kishor, P.B.: Deciphering the regulatory mechanisms of abiotic stress tolerance in plants by genomic approaches. - Gene 388: 1-13, 2007.

Stiller, I., Dulai, S., Kondrák, M., Tarnai, R., Szabó, L., Toldó, O., Bánfalvi, Z.: Effects of drought on water content and photosynthetic parameters in potato plants expressing the trehalose-6-phosphate synthase gene of Saccharomyces cerevisiae. - Planta 227: 299-308, 2008.

Studer, S., Narberhaus, F.: Chaperone activity and homo- and hetero-oligomer formation of bacterial small heat shock proteins. - J. biol. Chem. 275: 37212-37218, 2000.

Suárez, R., Calderón, C., Iturriaga, G.: Enhanced tolerance to multiple abiotic stresses in transgenic alfalfa accumulating trehalose. - Crop Sci. 49: 1791-1799, 2009.

Sun, W., Bernard, C., Cotte, B.V., Montagu, M.V., Verbruggen, N.: At-HSP17.6A, encoding a small heat-shock protein in Arabidopsis, can enhance osmotolerance upon overexpression. - Plant J. 27: 407-415, 2001.

Sun, W., Van Montagu, M., Verbruggen, N.: Small heat shock proteins and stress tolerance in plants. - Biochim. biophys. Acta 1577: 1-9, 2002.

Suzuki, N., Bajad, S., Shuman, J., Shulaev, V., Mittler, R.: The transcriptional co-activator mbflc is a key regulator of the thermotolerance in Arabidopsis thaliana. - J. biol. Chem. 283: 9269-9275, 2008.

Thomashow, M.F.: Role of cold-responsive genes in plant freezing tolerance. - Plant Physiol. 118: 1-7, 1998.

Thomashow, M.F.: Plant cold acclimation: freezing tolerance genes and regulatory mechanisms. - Annu. Rev. Plant. Biol. 50: 571-599, 1999.

Török, Z., Goloubinoff, P., Horvath, I., Tsvetkova, N.M., Glatz A., Balogh, G., Varvasovszki, V., Los, D.A., Vierling, E., Crowe, J.H., Vigh, L.: Synechocystis HSP17 is an amphitropic protein that stabilizes heat-stressed membranes and binds denatured proteins for subsequent chaperonemediated refolding. - Proc. nat. Acad. Sci. USA 98: 30983103, 2001.

Tran, L.S., Nakashima, K., Sakuma, Y., Simpson, S.D., Fujita, Y., Maruyama, K., Fujita, M., Seki, M., Shinozaki, K., Yamaguchi-Shinozaki, K.: Isolation and functional analysis of Arabidopsis stress inducible NAC transcription factors that bind to a drought responsive cis-element in the early responsive to dehydration stress 1 promoter. - Plant Cell 16: 2481-2498, 2004

Trujillo, L., Menendez, C., Ochogavia, M.E., Hernandez, I., Borras, O., Rodriguez, R., Coll, Y., Arrieta, J.G., Banguela, A., Ramirez, R., Hernandez, L.: Engineering drought and salt tolerance in plants using SodERF3, a novel sugarcane ethylene responsive factor. - Biotechnol. Apl. 26: 168-171, 2009.

Trujillo, L., Sotolongo, M., Menendez, C., Ochogava, M.E., Coll, Y., Hernandez, I., Borras-Hidalgo, O., Thomma, 
B.P.H.J., Vera, P., Hernandez, L.: SodERF3, a novel sugarcane ethylene responsive factor (ERF), enhances salt and drought tolerance when over-expressed in tobacco plants. - Plant Cell Physiol. 49: 512-515, 2008.

Tunnacliffe, A., Wise, M.J.: The continuing conundrum of the LEA proteins. - Naturwissenschaften 94: 791-812, 2007.

Tyerman, S.D., Bohnert, H.J., Maurel, C., Steudle, E., Smith, J.A.: Plant aquaporins: their molecular biology, biophysics and significance for plant water relations. - J. exp. Bot. 50: 1055-1071, 1999.

Valliyodan, B., Nguyen, H.: Understanding regulatory networks and engineering for enhanced drought tolerance in plants. Curr. Opin. Plant Biol. 9: 1-7, 2006.

Veinger, L., Diamant, L., Buchner, P., Goloubinoff, P.: The small heat-shock protein IbpB from Escherichia coli stabilizes stress denatured proteins for subsequent refolding by a multi-chaperone network. - J .biol. Chem. 273: 11032$11037,1998$.

Vendruscolo, E.C.G., Schuster, I., Pileggi, M., Scapim, C.A., Molinari, H.B.C., Marur, C.J., Vieira, L.G.E.: Stressinduced synthesis of proline confers tolerance to water deficit in transgenic wheat. - J. Plant Physiol. 164: 13671376, 2007.

Vierling, E.: The roles of heat-shock proteins in plants. - Ann. Rev. Plant Biol. 42: 579-620, 1991.

Vierling, E., Kimpel, J.A.: Plant responses to environmental stress. - Curr. Opin. Biotechnol. 3: 164-170, 1992.

Vij, S., Tyagi, A.K.: Emerging trends in the functional genomics of the abiotic stress response in crop plants. Plant Biotechnol. J. 5: 361-380, 2007.

Vinocur, B., Altman, A.: Recent advances in engineering plant tolerance to abiotic stress: achievements and limitations. Curr. Opin. Biotechnol. 16: 123-132, 2005.

Volkov, R.A., Panchuk, I.I., Mullineaux, P.M., Schoffl, F.: Heat stress-induced $\mathrm{H}_{2} \mathrm{O}_{2}$ is required for effective expression of heat shock genes in Arabidopsis. - Plant mol. Biol. 61: 733746, 2006.

Wang, Q.Y., Guan, Y.C., Wu, Y.R., Chen, H.L., Chen, F., Chu, C.C.: Overexpression of a rice OSDREBIF gene increases salt, drought and low temperature tolerance in both Arabidopsis and rice. - Plant mol. Biol. 67: 589-602, 2008.

Wang, W.X., Vinocur, B., Altman, A.: Plant responses to drought, salinity and extreme temperatures: towards genetic engineering for stress tolerance. - Planta 219: 1-14, 2003.

Wang, Y., Jiang, J., Zhao, X.,, Liu G., Yang, C., Zhan, L.: A novel LEA gene from Tamarix rossowii confers drought tolerance in transgenic tobacco. - Plant Sci. 171: 655-662, 2006.

Wang, Y., Ying, J., Kuzma, M., Chalifoux, M., Sample, A., McArthur, C., Uchacz, T., Sarvas, C., Wan, J., Dennis, D.T., McCourt, P., Huang, Y.: Molecular tailoring of farnesylation for plant drought tolerance and yield protection. - Plant J. 43: 413-424, 2005.

Wanner, L.A., Junttila, O.: Cold-induced freezing tolerance in Arabidopsis. - Plant Physiol. 120: 391-400, 1999.

Waters, E.R., Lee, G.J., Vierling, E.: Evolution, structure and function of the small heat shock proteins in plants. - J. exp. Bot. 47: 325-338, 1996.
Weston, D.J., Gunter, L.E., Rogers, A., Wullschleger, S.D.: Connecting genes, coexpression modules, and molecular signatures to environmental stress phenotypes in plants. BMC Syst. Biol. 2: 16, 2008.

Wise, M.J.: LEA ping to conclusions: a computational reanalysis of late embryogenesis abundant proteins and their possible roles. - BMC Bioinform. 4: 52, 2003.

Wise, M.J., Tunnacliffe, A.: POPP the question: what do LEA proteins do? - Trends Plant Sci. 9: 13-17, 2004.

Wollgiehn, R., Neumann, D.: Stress response of tomato cell cultures to toxic metals and heat shock: differences and similarities. - J. Plant Physiol. 146: 736-742, 1995.

Xiang, Y., Tang, N., Du, H., Ye, H., Xiong, L.: Charaterization of OsbZIP23 as a key player of the basic leucine zipper transcription factor family for conferring abscisic acid sensitivity and salinity and drought tolerance in rice. - Plant Physiol. 148: 1938-1952, 2008.

Xiao, B., Huang, Y., Tang, N., Xiong, L.: Over-expression of a $L E A$ gene in rice improves drought resistance under the field conditions. - Theor. appl. Genet. 115: 35-46, 2007.

Xu, D., Duan X., Wang, B., Hong B., Ho, T.H.D., Ho, D., Wu, R.: Expression of a late embryogenesis abundant protein gene, $H V A 1$, from barley confers tolerance to water deficit and salt stress in transgenic rice. - Plant Physiol. 110: 249257, 1996.

Yamada, M., Morishita H., Urano, K., Shiozaki N., YamaguchiShinozaki, K., Shinozaki, K., Yoshiba, Y.: Effects of free proline accumulation in petunias under drought stress. - J. exp. Bot. 56: 1975-1981, 2005.

Yamaguchi-Shinozaki, K., Shinozaki, K.: Organization of cisacting regulatory elements in osmotic- and cold-stressresponsive promoters. - Trends Plant Sci. 10: 88-94, 2005.

Yoshida, T., Sakuma, Y., Todaka, D., Maruyama, K., Qin, F., Mizoi, J., Kidokoro, S., Fujita, Y., Shinozak,i K., Yamaguchi-Shinozak,i K.: Functional analysis of an Arabidopsis heat-shock transcription factor HsfA3 in the transcriptional cascade downstream of the DREB2A stressregulatory system. - Biochem. biophys. Res. Commun. 368: 515-521, 2008.

Yu, H., Chen, X., Hong, Y-Y., Wang, Y., Xu, P., Ke, S-D., Liu, H-Y., Zhu, J-K., Oliver, D.J., Xiang, C-B.: Activated expression of an Arabidopsis HD-START protein confers drought tolerance with improved root system and reduced stomatal density. - Plant Cell 20: 1134-1151, 2008.

Yu, Q., Hu, Y., Li, J., Wu, Q., Lin, Z.: Sense and antisense expression of plasma membrane aquaporin BnPIPl from Brassica napus in tobacco and its effects on plant drought resistance. - Plant Sci. 169: 647-656, 2005.

Zhang, G., Chen, M., Li, L., Xu, Z., Chen, X., Guo, J., Ma, Y.: Overexpression of the soybean GmERF3 gene, an AP2/ERF type transcription factor for increased tolerances to salt, drought and diseases in transgenic tobacco. - J. exp. Bot. 60: 3781-3796, 2009.

Zhu, J.K.: Salt and drought stress signal transduction in plants. Annu. Rev. Plant Biol. 53: 247-273, 2002.

Zou, M., Guan, Y., Ren, H., Zhang, F., Chen, F.: A bZIP transcription factor, OsABI5, is involved in rice fertility and stress tolerance. - Plant mol. Biol. 66: 675-683, 2008. 